\title{
Effect of Antenatal Dexamethasone on Respiratory Distress in Late Preterm Infants: Results from the First Vietnamese Matched Cohort Study
}

\section{Tran Tuan Hung Ho}

Hue University of Medicine and Pharmacy: Truong Dai hoc Y Duoc Hue

\section{Quang Vinh Truong}

Hue University of Medicine and Pharmacy: Truong Dai hoc Y Duoc Hue

Thi Kim Anh Nguyen

Hue University of Medicine and Pharmacy: Truong Dai hoc Y Duoc Hue

Minh Tam Le

Hue University of Medicine and Pharmacy: Truong Dai hoc Y Duoc Hue

Vu Quoc Huy Nguyen ( $\nabla$ nvqhuy@huemed-univ.edu.vn )

Hue University of Medicine and Pharmacy https://orcid.org/0000-0002-4744-7059

Research article

Keywords: Respiratory distress, late preterm infant, antenatal dexamethasone

Posted Date: January 16th, 2021

DOl: https://doi.org/10.21203/rs.3.rs-146925/v1

License: (c) (i) This work is licensed under a Creative Commons Attribution 4.0 International License.

Read Full License

Version of Record: A version of this preprint was published at BMC Pregnancy and Childbirth on August 7th, 2021. See the published version at https://doi.org/10.1186/s12884-021-04019-6. 


\section{Abstract}

\section{Background}

Respiratory distress (RD) is one of the leading causes of early neonatal morbidity and mortality in late preterm infants (LPIs) worldwide. This study aimed to evaluate the effect of antenatal dexamethasone on the $\mathrm{RD}$ rate in preterm newborns between $340 / 7$ weeks and 36 6/7 weeks of gestation.

\section{Methods}

This was a prospective cohort study of 78 women with singleton pregnancy who were in threatened preterm birth and had not received prior dexamethasone who were admitted between 34 0/7 weeks and 36 6/7 weeks at Hue University of Medicine and Pharmacy Hospital from June 2018 to May 2020. The matched control group (no dexamethasone) included 78 pregnant women with threatened late preterm births who were at similar gestational ages and estimated fetal weights as the treatment group. The treatment group received $6 \mathrm{mg}$ intramuscular dexamethasone every 12 hours for a total of 4 doses or until delivery. Primary outcome was the rate of neonatal RD. Secondary neonatal outcomes included the need for respiratory support, neonatal intensive care unit (NICU) admission, hypoglycemia, necrotizing enterocolitis, intraventricular hemorrhage, and neonatal death. Statistical analyses were performed by using SPSS software.

\section{Results}

The rate of RD in LPI was significantly lower in the treatment group than in the matched control group ( $10.3 \%$ vs. $23.1 \%$, respectively), with relative risk [RR] 0.44; $95 \%$ confidence interval [Cl] $0.21-0.96$ and $p$ $=0.03$. Neonatal hypoglycemia was more common in the dexamethasone group than in the matched group ( $25.6 \%$ vs. $12.8 \%$, respectively; $R R, 2.00 ; 95 \% \mathrm{Cl}, 1.00-3.99 ; p=0.04)$. There were no significant between-group differences in the incidence of respiratory support, NICU admission or length of hospital stay.

\section{Conclusions}

Administration of antenatal dexamethasone to women at risk for late preterm birth could significantly reduce the rate of respiratory distress in late preterm infants.

\section{Background}

Preterm birth is defined as babies born alive before the completion of 37 weeks of pregnancy [1]. Preterm infants are at high risk of health and illness in the future, related to survival and quality of life. According to the World Health Organization, 15 million preterm babies are born annually, and the rate of preterm birth is rising [1]. Infants who are born from 34 weeks - 36 weeks and 6 days, also known as late preterm infants, are at higher risks of respiratory distress and other complications than those born at term [2]. In 2010 , the rate of preterm birth from 32 weeks to 37 weeks was approximately $80 \%$ in Southeast Asia in 
general, particularly in Vietnam [1]. Respiratory distress syndrome (RDS) is one of the leading causes of early neonatal morbidity and mortality. Although the incidence of RDS is less common after 34 weeks of gestation, late preterm newborns are more likely to experience RDS and other neonatal respiratory complications than infants born at term [3].

Prophylactic corticosteroids in singleton preterm pregnancies accelerate lung maturation and reduce the rate of RDS. There is strong evidence that corticosteroids can reduce the risk of neonatal respiratory complications when administered before 34 weeks of gestation [4], [5]. Administration of antenatal corticosteroids (ACS) has become more common following a consensus from the National Institutes of Health (NIH) in 1994 [6]. Both betamethasone and dexamethasone are effective in accelerating fetal lung maturation and are the most widely approved for use in ACS therapy [7]. However, evidence for the benefit of ACS in preterm pregnancy between 34 weeks 0 day and 36 weeks 6 days is controversial due to a lack of data. To clarify this issue, the Antenatal Late Preterm Steroids (ALPS) trial was conducted [8]. This was a multicenter, randomized controlled trial that assessed the benefits of betamethasone administration for women with singleton gestation pregnancies at risk for late preterm birth. The ALPS trial findings were published in early 2016 and showed a significant reduction in neonatal respiratory complications in response to betamethasone administration. With publication of the ALPS trial, the use of antenatal corticosteroids in this population has become increasingly common in clinical practice for the management of pregnancies at risk for late preterm birth [9]. Recently, the American College of Obstetricians and Gynecologists recommended a single course of corticosteroids for pregnant women at risk of late preterm delivery within 7 days who have not received a previous course of antenatal corticosteroids if proceeding with induction or delivery in no less than 24 hours and no more than 7 days [10].

In Vietnam, medical literature searches through the end of 2017 retrieved no work on the use of ACS in the late preterm period, and current national guidelines on reproductive health services have not covered this issue. Furthermore, neonatal care interventions for late preterm newborns are considerably limited in low-resource countries. This study aimed to evaluate the effect of antenatal dexamethasone on the rate of respiratory distress in premature newborns between 34 0/7 weeks and 36 6/7 weeks of gestation.

\section{Methods}

This prospective cohort study was performed at the Departments of Obstetrics \& Gynecology of the Hue University of Medicine and Pharmacy Hospital between June 2018 and May 2020.

Study subjects included 78 pregnant women with singleton pregnancies from 34 0/7 weeks to 36 6/7 weeks, estimated based on the first day of the last menstrual period or the estimated delivery date of first trimester ultrasound, having one or more of the following signs: 1 ) spontaneous rupture of the membranes; 2) preterm labor, defined as having 4 contractions in 20 minutes or 8 contractions in 60 minutes causing cervical dilation, or cervical dilation $\geq 2 \mathrm{~cm}$ in the presence of contractions; and 3) high probability of indication for late preterm delivery: uncontrolled bleeding placenta previa, placental 
abruption, or elective cesarean section due to maternal medical conditions. Exclusion criteria were previous administration of dexamethasone during pregnancy, stillbirth and life-threatening fetal anomalies, gestational diabetes, chorioamnionitis, or contraindications for dexamethasone. The treatment group received dexamethasone $6 \mathrm{mg}$ intramuscularly every 12 hours for a total of 4 doses or until delivery. The matched control group included 78 newborn infants who were at similar gestational age at delivery with similar estimated fetal weight to the treatment group born to mothers who had not received dexamethasone before delivery.

Maternal data collection was performed by interviewing and examining pregnant women with respect to maternal age, gravidity, history of preterm delivery, and gestational age. Follow-up was performed during the treatment course to collect data on the cause of pregnancy termination, mode of delivery and birth weight.

Late preterm newborns were evaluated after birth to collect the following outcome information:

- The primary outcome was the rate of respiratory distress within 72 hours after birth, diagnosed by the presence of one or more of the following criteria: 1) dyspnea (respiratory rate $\geq 60 /$ minute or $<30 /$ minute, apnea $\geq 20$ seconds); 2) central cyanosis (blue tongue and lips); 3) chest indrawing and 4) grunting on expiration [11].

- Neonatal secondary outcomes included the following: respiratory support (supplemental oxygen through nasal cannula, the use of continuous positive airway pressure (CPAP) or mechanical ventilation), surfactant administration, respiratory distress syndrome, defined as the presence of clinical signs of respiratory distress that include a rapid onset of severe hypoxemia and abnormal chest radiography, Apgar's score $<7$ at 1 minute and 5 minutes after birth, need for resuscitation at birth, neonatal intensive care unit (NICU) admission and length of hospital stay; maximal follow-up time of first 28 days of life.

- Other neonatal outcomes included the following: early-onset neonatal sepsis, jaundice requiring phototherapy, hypoglycemia (defined as a glucose level less than $2.2 \mathrm{mmol} / \mathrm{L}$ ), intraventricular hemorrhage, necrotizing enterocolitis, and neonatal death before discharge (within the first 28 days of life).

Maternal outcomes included chorioamnionitis (maternal fever $>37.8^{\circ} \mathrm{C}$, maternal tachycardia $>100 / \mathrm{min}$, fetal tachycardia $>160 / \mathrm{min}$, foul smelling amniotic fluid, white blood cell count $>15.000$, C-reactive protein $>20 \mathrm{mg} / \mathrm{L}$ ), endometritis (maternal fever $>37.8^{\circ} \mathrm{C}$, maternal tachycardia $>100 / \mathrm{min}$, uterine tenderness, foul smelling lochia), retained placenta and the length of hospital stay after delivery.

Data were collected and analyzed using Statistical Package for the Social Sciences (SPSS) software, version 26.0. Continuous variables are expressed as the mean \pm standard deviation or median 
(interquartile range - IQR) and were compared using t-tests (for normal distribution) and Mann-Whitney tests (for nonnormal distribution). Categorical variables were compared with Chi-square and Fisher's exact tests. Relative risks (RRs) and 95\% confidence intervals (Cls) are reported. $\mathrm{P}<0.05$ was considered statistically significant.

This study protocol was approved by the Ethics Committee for Biomedical Research of Hue University of Medicine and Pharmacy, approval number H2018/357. Written consent was obtained from all study participants before their enrollment.

\section{Results}

Table 1 shows that there were no significant differences between groups with respect to maternal age, gravidity, history of prematurity, or method of delivery. The most frequent cause of delivery was rupture of membranes (43.6\%), and there was a statistically significant difference between the dexamethasone group and the matched group ( $26.9 \%$ vs. $59.0 \%, p<0.0001$, respectively). 
Table 1

General characteristics of the study subjects.

\begin{tabular}{|c|c|c|c|}
\hline Characteristics & $\begin{array}{l}\text { Dexamethasone group } \\
(\mathrm{N}=78)\end{array}$ & $\begin{array}{l}\text { Matched } \\
\text { group } \\
(\mathrm{N}=78)\end{array}$ & p-value \\
\hline Maternal age (year) Mean $( \pm S D)$ & $28.5 \pm 5.1$ & $27.6 \pm 6.0$ & 0.35 \\
\hline \multicolumn{4}{|l|}{ Gravidity, n (\%) } \\
\hline 1 & $35(44.9)$ & $33(42.3)$ & 0.75 \\
\hline$\geq 2$ & $43(55.1)$ & $45(57.7)$ & \\
\hline History of preterm birth, n (\%) & $8(10.3)$ & $7(9.0)$ & 0.79 \\
\hline \multicolumn{4}{|l|}{ Gestational age at birth, n (\%) } \\
\hline $34^{0 / 7}-34^{6 / 7}$ & $6(7.7)$ & $5(6.4)$ & 0.75 \\
\hline $35^{0 / 7}-35^{6 / 7}$ & $31(39.7)$ & $31(39.7)$ & 1.00 \\
\hline $36^{0 / 7}-36^{6 / 7}$ & $41(52.6)$ & $42(53.8)$ & 0.87 \\
\hline Birth weight, (gram) Mean ( \pm SD) & $2547 \pm 507$ & $2488 \pm 344$ & 0.40 \\
\hline \multicolumn{4}{|l|}{ Causes of preterm birth, $n$ (\%) } \\
\hline Rupture of membranes & $21(26.9)$ & $46(59.0)$ & $<0.0001$ \\
\hline Preterm labor & $41(52.6)$ & $27(34.6)$ & 0.02 \\
\hline Preeclampsia & $6(7.7)$ & $1(1.3)$ & 0.12 \\
\hline Previa placenta & $3(3.8)$ & 0 & - \\
\hline Placental abruption & 0 & $1(1.3)$ & - \\
\hline Fetal compromise & $6(7.7)$ & $2(2.6)$ & 0.28 \\
\hline Elective & $1(1.3)$ & 0 & - \\
\hline \multicolumn{4}{|l|}{ Mode of delivery, n (\%) } \\
\hline Normal delivery & $48(61.5)$ & $53(67.9)$ & 0.40 \\
\hline Cesarean delivery & $30(38.5)$ & $22(28.2)$ & 0.17 \\
\hline Operative delivery (forceps) & 0 & $3(3.8)$ & - \\
\hline
\end{tabular}

The rate of respiratory distress was significantly lower in the dexamethasone group than in the matched control group (10.3\% vs. $23.1 \%$, respectively; RR, $0.44 ; 95 \% \mathrm{Cl}, 0.21-0.96 ; \mathrm{p}=0.03$ ) (Table 2 ). 
Table 2

Neonatal respiratory outcomes and related conditions between the dexamethasone and matched control groups.

\begin{tabular}{|c|c|c|c|c|}
\hline Outcomes & $\begin{array}{l}\text { Dexamethasone } \\
\text { group } \\
(\mathrm{N}=78)\end{array}$ & $\begin{array}{l}\text { Matched } \\
\text { group } \\
(\mathrm{N}=78)\end{array}$ & $\begin{array}{l}\text { RR } \\
(95 \% \mathrm{Cl})\end{array}$ & $\begin{array}{l}\mathrm{p}- \\
\text { value }\end{array}$ \\
\hline Respiratory distress, n (\%) & $8(10.3)$ & $18(23.1)$ & $\begin{array}{l}0.44(0.21- \\
0.96)\end{array}$ & 0.03 \\
\hline \multicolumn{5}{|l|}{ Respiratory support, n (\%) } \\
\hline Supplemental oxygen & $15(19.2)$ & $19(24.4)$ & \multirow{3}{*}{$\begin{array}{l}0.79(0.43- \\
1.44) \\
0.40(0.08- \\
2.00)\end{array}$} & 0.44 \\
\hline CPAP & $2(2.6)$ & $5(6.4)$ & & 0.44 \\
\hline \multirow[t]{2}{*}{ Mechanical ventilation } & \multirow[t]{2}{*}{$1(1.3)$} & \multirow[t]{2}{*}{$1(1.3)$} & & \multirow[t]{2}{*}{1.00} \\
\hline & & & $\begin{array}{l}1.00(0.06- \\
15.71)\end{array}$ & \\
\hline Surfactant use, n (\%) & $1(1.3)$ & $1(1.3)$ & $\begin{array}{l}1.00(0.06- \\
15.71)\end{array}$ & 1.00 \\
\hline Resuscitation at birth, n (\%) & $10(12.8)$ & $11(14.1)$ & $\begin{array}{l}0.91(0.41- \\
2.02)\end{array}$ & 0.82 \\
\hline \multicolumn{5}{|l|}{ Apgar score, n (\%) } \\
\hline$<7$ at 1 minute & $2(2.6)$ & $2(2.6)$ & \multirow{2}{*}{$\begin{array}{l}1.00(0.95- \\
1.05)^{(-} \\
-\end{array}$} & 1.00 \\
\hline$<7$ at 5 minutes & $1(1.3)$ & 0 & & - \\
\hline Respiratory distress syndrome, $\mathrm{n}(\%)$ & $1(1.3)$ & $1(1.3)$ & $\begin{array}{l}1.00(0.06- \\
15.71)\end{array}$ & 1.00 \\
\hline NICU admission, n (\%) & $26(32.1)$ & $32(39.5)$ & $\begin{array}{l}0.81(0.54- \\
1.23)\end{array}$ & 0.33 \\
\hline $\begin{array}{l}\text { Median length of hospital stay (IQR), } \\
\text { days }\end{array}$ & $5(3.0-6.0)$ & $\begin{array}{l}5(3.0- \\
6.25)\end{array}$ & - & 1.00 \\
\hline
\end{tabular}

Nevertheless, dexamethasone did not reduce the need for respiratory support. The rate of respiratory distress syndrome, Apgar score $<7$, NICU admission, need for resuscitation at birth, surfactant use and length of hospital stay were not significantly different between the two groups.

There were no cases of intraventricular hemorrhage, necrotizing enterocolitis, or neonatal death in the two groups, as shown in Table 3. Compared to the control group, dexamethasone did not significantly reduce the incidence of early-onset neonatal sepsis or jaundice requiring phototherapy $(p>0.05)$. However, the rate of hypoglycemia was significantly higher in the dexamethasone group than in the matched group (25.6\% vs. $12.8 \%$; RR, $2.00 ; 95 \% \mathrm{Cl}, 1.00-3.99 ; \mathrm{p}=0.04$ ). 
Table 3

Other neonatal secondary outcomes.

\begin{tabular}{|lllll|}
\hline $\begin{array}{l}\text { Outcomes, } \\
\mathbf{n}(\%)\end{array}$ & $\begin{array}{l}\text { Dexamethasone } \\
\text { group } \\
\mathbf{( N = 7 8 )}\end{array}$ & $\begin{array}{l}\text { Matched } \\
\text { group } \\
\mathbf{( N = 7 8 )}\end{array}$ & $\begin{array}{l}\text { RR } \\
(\mathbf{9 5 \%} \mathbf{C l})\end{array}$ & p-value \\
\hline Early-onset neonatal sepsis & $16(20.5)$ & $22(28.2)$ & $0.73(0.41-1.28)$ & 0.26 \\
\hline $\begin{array}{l}\text { Jaundice requiring } \\
\text { phototherapy }\end{array}$ & $12(15.4)$ & $17(21.8)$ & $0.71(0.36-1.38)$ & 0.30 \\
\hline Hypoglycemia & $20(25.6)$ & $10(12.8)$ & $2.00(1.00-3.99)$ & 0.04 \\
\hline Intraventricular hemorrhage & 0 & 0 & - & - \\
\hline Necrotizing enterocolitis & 0 & 0 & - & - \\
\hline Neonatal death & 0 & 0 & - & - \\
\hline
\end{tabular}

Regarding maternal outcomes, as shown in Table 4, there were no significant between-group differences in the incidence of endometritis, chorioamnionitis or retained placenta. The median postpartum length of hospital stay was also similar between the two groups.

Table 4

Maternal outcomes.

\begin{tabular}{|c|c|c|c|c|}
\hline Outcome & $\begin{array}{l}\text { Dexamethasone } \\
\text { group } \\
(\mathrm{N}=78)\end{array}$ & $\begin{array}{l}\text { Matched } \\
\text { group } \\
(\mathrm{N}=78)\end{array}$ & $\begin{array}{l}\text { RR } \\
(95 \% \mathrm{Cl})\end{array}$ & $\begin{array}{l}\mathrm{p}- \\
\text { value }\end{array}$ \\
\hline Chorioamnionitis, n (\%) & 0 & $1(1.3)$ & - & - \\
\hline Endometritis, n (\%) & 0 & 0 & - & - \\
\hline Retained placenta, n (\%) & $9(11.5)$ & $7(9.0)$ & $\begin{array}{l}1.29(0.50- \\
3.29)\end{array}$ & 0.60 \\
\hline $\begin{array}{l}\text { Median postpartum length of hospital stay } \\
\text { (IQR), days }\end{array}$ & $5(3.0-5.0)$ & $\begin{array}{l}4(3.0- \\
5.0)\end{array}$ & - & 0.32 \\
\hline
\end{tabular}

\section{Discussion}

To date, many studies around the world have been conducted to evaluate the health and economic effects of ACS administered to a special population of late preterm infants. The supplementation of pregnant women with antenatal corticosteroids between 34 weeks and 36 weeks 6 days was accepted as an effective approach that can significantly reduce the cost and acute morbidity associated with late preterm birth [12]. The mechanism that causes respiratory distress in babies born between 22 weeks and 34 weeks of gestation, including surfactant deficiency and immature development of the fetal lung, can 
also affect late preterm infants. Lack of the epithelial sodium channel responsible for clearance of the fluid and deficiency of pulmonary surfactant plays a key role in the pathophysiology of respiratory morbidity [2]. Antenatal corticosteroids may have an impact on both surfactant maturity and fetal lung fluid clearance in late preterm newborns [13]. Currently, Vietnam is a lower middle-income country, but preterm newborn care is still limited. The economic costs of preterm birth are large in terms of neonatal intensive care and long-term complications [1]. Therefore, a low-cost intervention, such as antenatal dexamethasone, may indeed help to alleviate the neonatal interventions needed in Vietnam.

Our study objective was to determine the efficacy of antenatal dexamethasone in reducing the rate of respiratory distress in late preterm infants. As mentioned above, we found that dexamethasone administration to women at risk at $340 / 7$ weeks $-366 / 7$ weeks of gestation reduced the rate of respiratory distress (RR, $0.44 ; 95 \% \mathrm{Cl}, 0.21-0.96 ; \mathrm{p}=0.03$ ). Previously, Yinon et al. (2012) conducted a retrospective cohort study to compare the outcomes of infants born between 34 and 37 weeks of gestation who had either received betamethasone or not. The rate of the composite respiratory morbidity outcome was significantly higher in the nontreatment group than in the betamethasone group $(21 \% \mathrm{vs}$. $8.4 \%$, respectively; $p=0.02$ ). However, this was a retrospective cohort study design, and the authors could not control for potential confounding factors [14]. According to Attawattanakul (2015), dexamethasone administration in late preterm labor significantly decreased the rate of respiratory distress without increasing the rate of adverse events. Furthermore, only $6 \%$ of participants completed the full course of antenatal dexamethasone [15]. Most recently, both Gyamfi-Bannerman et al. (2016) and Uquillas et al. (2020) found that antenatal betamethasone decreased the need for substantial respiratory support during the first 72 hours of late preterm newborns after birth $(p=0.02)$ [8], [16]. Uquillas et al's study was also a retrospective cohort study, so they could not control for differences in subgroup gestational age (34 weeks, 35 weeks and 36 weeks of gestation). Despite being the largest trial, it is important to note that only $60 \%$ of the study group completed the full course of betamethasone in the Gyamfi-Bannerman et al' trial.

In addition, there are other studies that reported opposite results. A randomized controlled trial conducted by Porto et al showed that the rate of respiratory morbidity was similar between betamethasone and placebo groups ( $25 \%$ vs. $23 \%$, respectively). They concluded that antenatal treatment with corticosteroids was not effective in reducing neonatal respiratory morbidity. However, 43 pregnant women (13\%) were discharged and lost to follow-up. [17]. Recently, Balreldin et al. (2020) even concluded that the rate of respiratory distress in the group using ACS was higher than in the group without ACS (6\% vs. $4.7 \%$, respectively) [18]. These differences may be due to the different sample sizes and trial designs. Balreldin et al pointed out that the weakness in their study was the limited sample size; therefore, their analysis had inadequate power to identify differences. In addition, our study is the first in Vietnam to use dexamethasone to determine the benefits of antenatal corticosteroids on respiratory distress reduction in late preterm infants.

In our matched cohort study, there were no significant differences between groups in baseline characteristics, including maternal age, history of prematurity, gravidity, and method of delivery. The most 
frequent cause of delivery was premature rupture of the membranes (43.6\%), followed by preterm labor (42.9\%). Compared to the matched group, the incidence of membrane rupture in the dexamethasone group was lower $(p<0.0001)$, but the incidence of preterm labor was higher $(p=0.02)$. These differences may be explained by the longer the rupture of membranes, the more limited the indication of dexamethasone to be used.

In our findings, there was a difference in the level of breathing difficulty related to respiratory distress in late preterm infants between the two groups. In particular, there were 2 infants with moderate levels in the dexamethasone group and 10 infants with moderate levels in the matched group. Two cases with severe breathing difficulty in the two groups were due to respiratory distress syndrome (stage III) and were treated with mechanical ventilation and surfactant therapy. As mentioned above, dexamethasone primarily reduced the moderate level of breathing difficulty. Although the difference was not statistically significant, antenatal dexamethasone may help improve the level of breathing difficulty in late preterm newborns.

Our study showed that there was a significant reduction in the rate of respiratory distress. Nevertheless, the rate of NICU admission, the need for respiratory support, respiratory distress syndrome, surfactant use, and Apgar score $<7$ were not significantly different between the dexamethasone and matched control groups. We found that there were cases of neonatal respiratory distress at different levels, but Apgar score $\geq 7$ at 1 minute and 5 minutes after birth accounted for the majority in the two groups. Although good resuscitation at birth significantly improved the Apgar score, some infants showed signs of respiratory distress within 72 hours after birth (tachypnea, grunting, chest indrawing, etc.) and the need for respiratory support. Table 2 also shows that dexamethasone did not shorten the length of hospital stay for infants. This could be explained by many other factors affecting the length of hospital stay of late preterm newborns, including gestational age, birth weight, sex, method of delivery and neonatal complications [19].

Furthermore, administration of dexamethasone did not significantly improve the rates of short-term morbidity or complications of late preterm infants, consisting of jaundice requiring phototherapy, earlyonset neonatal sepsis, intraventricular hemorrhage, necrotizing enterocolitis and neonatal death. Notably, the rate of neonatal hypoglycemia was higher in the dexamethasone group than in the control group ( $25.6 \%$ vs. $12.8 \%$, respectively; RR, $2.00 ; 95 \% \mathrm{Cl}, 1.00-3.99 ; \mathrm{p}=0.04)$. Few trials of antenatal corticosteroids have recorded the same result on neonatal hypoglycemia in the late preterm period. According to Ramadan et al. (2016), infants in the betamethasone group had a higher incidence of neonatal hypoglycemia $(p=0.04)$ [20]. Gyamfi-Bannerman $(2016)$ also demonstrated that betamethasone increased the rate of neonatal hypoglycemia ( $24.0 \%$ vs. $15.0 \%$, respectively; RR, $1.60 ; 95 \%$ $\mathrm{Cl}, 1.60-1.87 ; \mathrm{p}<0.001)$, although there were no reported adverse events related to neonatal hypoglycemia, and the condition was self-limiting [8]. Our findings are consistent with the results of Gyamfi-Bannerman. Accordingly, we support monitoring blood glucose of newborns in the late preterm period who were exposed to antenatal dexamethasone. 
The results in Table 4 show that dexamethasone administration did not increase the risk of infection for the mother. There was only 1 case of chorioamnionitis in the control group, and there were no diagnosed endometritis cases in either group. These findings are consistent with the results of Gyamfi-Bannerman et al. [8]. There was no significant between-group difference in the incidence of retained placenta. The maternal length of hospital stay after delivery in the dexamethasone group was slightly higher than in the matched group, but the difference was not statistically significant $(p>0.05)$. This could be explained by the higher rate of cesarean delivery in the dexamethasone group than in the matched group (38.5\% vs. $28.2 \%$, respectively). In clinical practice at our study center, the maternal length of hospital stay after birth is usually 5 days for cesarean delivery and 3 days for normal delivery. Therefore, dexamethasone was not associated with an increased length of hospital stay of the mother after delivery.

A previously published study evaluated the long-term impact of antenatal corticosteroids. In 2013, a follow-up study was conducted to evaluate the long-term behavioral, cognitive and developmental outcomes of children aged 8-15 years who were born preterm in a previous study with corticosteroid administration, and they did not exhibit any adverse events [21]. In this study, only short-term complications of late preterm infants within 72 hours after birth were assessed, not long-term complications. Another limitation is the nature of matched-cohort studies rather than randomized control trials to increase the power of the study results.

\section{Conclusions}

Our study showed that the administration of antenatal dexamethasone in the late preterm period significantly reduced the rate of respiratory distress in newborns. Dexamethasone administration significantly increased the rate of neonatal hypoglycemia but not the rates of other maternal or neonatal adverse events.

\section{Abbreviations}

ACS: antenatal corticosteroids, LPI: late preterm infant, NICU: neonatal intensive care unit, RD: respiratory distress

\section{Declarations}

\section{Ethics approval and consent to participate}

Ethical approval was obtained from Hue University of Medicine and Pharmacy's Ethics Committee for Biomedical Research, Approval No. H2018/357.

Written consent was obtained from all study participants before their enrollment.

\section{Consent for publication}


Not applicable.

\section{Availability of data and materials}

The datasets used and/or analyzed during the current study are available from the corresponding author on reasonable request.

\section{Competing interests}

The authors declare that they have no competing interests.

\section{Funding}

Not applicable.

\section{Authors' contributions}

H. T. T. H., T. Q. V., N. T. K. A., L. M. T., and N. V. Q. H.: study design.

H. T. T. H., T. Q. V., N. T. K. A., L. M. T., and N. V. Q. H.: acquisition, analysis, and interpretation of data.

H. T. T. H., L. M. T. N., and N. V. Q. H.: drafted the work and substantively revised it.

All authors have approved the submitted version of the manuscript.

\section{Acknowledgments}

The authors would like to thank Dr. Nguyen Thi Thanh Binh, Department of Pediatrics, Hue University of Medicine and Pharmacy and Hospital, Vietnam, for support during infant data collection.

\section{Author information}

Ho Tran Tuan Hung: MD, Chief Resident, Department of Obstetrics \& Gynecology, Hue University of Medicine and Pharmacy, Hue University, Hue 49120, Vietnam

Truong Quang Vinh: Assoc. Professor, MD, PhD, Department of Obstetrics \& Gynecology, Hue University of Medicine and Pharmacy, Hue University, Hue 49120, Vietnam

Nguyen Thi Kim Anh: MD, PhD, Department of Obstetrics \& Gynecology, Hue University of Medicine and Pharmacy, Hue University, Hue 49120, Vietnam 
Le Minh Tam: Assoc. Professor, MD, PhD, Department of Obstetrics \& Gynecology, Hue University of Medicine and Pharmacy, Hue University, Hue 49120, Vietnam

Nguyen Vu Quoc Huy: Professor, MD, PhD, Department of Obstetrics \& Gynecology, Hue University of Medicine and Pharmacy, Hue University, Hue 49120, Vietnam

\section{References}

1. World Health Organization. Born too soon: the global action report on preterm birth. Geneva: World Health Organization; 2012.

2. Raju TN, Higgins RD, Stark AR, Leveno KJ. Optimizing care and outcome for late-preterm (near-term) infants: a summary of the workshop sponsored by the National Institute of Child Health and Human Development. Pediatrics. 2006;118(3):1207-14.

3. Martin JA, Hamilton BE, Osterman MJ, Curtin SC, Matthews TJ. Births: final data for 2013. Natl Vital Stat Rep. 2015;64(1):1-65.

4. Crowley P, Chalmers I, Keirse MJNC. The effects of corticosteroid administration before preterm delivery: an overview of the evidence from controlled trials. BJOG: An International Journal of Obstetrics Gynaecology. 1990;97(1):11-25.

5. Liggins GC, Howie RN. A controlled trial of antepartum glucocorticoid treatment for prevention of the respiratory distress syndrome in premature infants. Pediatrics. 1972;50(4):515-25.

6. National Institutes of Health. Effect of corticosteroids for fetal maturation on perinatal outcomes. NIH Consens Statement. 1994;12(2):1-24.

7. World Health Organization. WHO recommendation on use of either dexamethasone or betamethasone as the antenatal corticosteroid of choice. Geneva: World Health Organization; 2015.

8. Gyamfi-Bannerman C, Thom EA, Blackwell SC, Tita AT, Reddy UM, Saade GR, et al. Antenatal Betamethasone for Women at Risk for Late Preterm Delivery. N Engl J Med. 2016;374(14):1311-20.

9. Committee Opinion No. 713: Antenatal Corticosteroid Therapy for Fetal Maturation. Obstet Gynecol. 2017;130(2):e102-e9.

10. Prelabor Rupture of Membranes. ACOG Practice Bulletin Summary, Number 217. Obstetrics Gynecology. 2020;135(3):739-43.

11. World Health Organization. Managing newborn problems: a guide for doctors, nurses and midwives. Geneva: World Health Organization; 2003.

12. Bastek JA, Langmuir H, Kondapalli LA, Paré E, Adamczak JE, Srinivas SK. Antenatal corticosteroids for late-preterm infants: a decision-analytic and economic analysis. ISRN Obstet Gynecol. 2012;2012:491595.

13. Jain L. Respiratory morbidity in late-preterm infants: prevention is better than cure! Am J Perinatol. 2008;25(2):75-8. 
14. Yinon Y, Haas J, Mazaki-Tovi S, Lapidot N, Mazkereth R, Hourvitz A, et al. Should patients with documented fetal lung immaturity after 34 weeks of gestation be treated with steroids? Am J Obstet Gynecol. 2012;207(3):222. .e1-.e4.

15. Attawattanakul N, Tansupswatdikul P. Effects of Antenatal Dexamethasone on Respiratory Distress in Late Preterm Infant: a randomized controlled trial. Thai Journal of Obstetrics Gynaecology. 2015;23:25-33.

16. Uquillas KR, Lee RH, Sardesai S, Chen E, Ihenacho U, Cortessis VK, et al. Neonatal hypoglycemia after initiation of late preterm antenatal corticosteroids. J Perinatol. 2020;40(9):1339-48.

17. Porto AM, Coutinho IC, Correia JB, Amorim MM. Effectiveness of antenatal corticosteroids in reducing respiratory disorders in late preterm infants: randomised clinical trial. BMJ. 2011;342:d1696.

18. Badreldin N, Willert GG, Henricks AA, Peaceman A, Caldarelli LA, Yee LM. Implementation of an antenatal late-preterm corticosteroid protocol at a high-volume tertiary care center. American Journal of Obstetrics Gynecology MFM. 2020;2(1):100076.

19. Aly H, Hoffman H, El-Dib M, Said L, Mohamed M. Factor affecting length of stay in late preterm infants: an US national database study. The Journal of Maternal-Fetal Neonatal Medicine. 2015;28(5):598-604.

20. Ramadan MK, Hussein G, Saheb W, Rajab M, Mirza FG. Antenatal corticosteroids in the late preterm period: A prospective cohort study. J Neonatal Perinatal Med. 2016;9(1):15-21.

21. Stutchfield PR, Whitaker R, Gliddon AE, Hobson L, Kotecha S, Doull IJ. Behavioural, educational and respiratory outcomes of antenatal betamethasone for term caesarean section (ASTECS trial). Arch Dis Child Fetal Neonatal Ed. 2013;98(3):F195-200. 